\title{
DIAGNÓSTICO BÁSICO DO SISTEMA DE DRENAGEM EM PIUMHI COM APLICAÇÃO DE MODELAGEM GIS ${ }^{1}$
}

\author{
Gabriel Soares Silva ${ }^{2}$ \\ Germano de Oliveira Mattosinho
}

\begin{abstract}
RESUMO
O padrão de urbanização brasileiro convergiu para uma infraestrutura inconsistente e seus problemas crônicos são históricos devido à expansão urbana nos entornos dos mananciais. Dentro desses desafios, surge a oportunidade para inserção de conceitos de Engenharia para sanar essas deficiências. Neste estudo, no município de Piumhi/Minas Gerais, observa-se que os impactos socioambientais, ocasionados por meio do crescimento populacional desordenado e corroborado com uma antiga infraestrutura, levaram alguns pontos localizados no município a não ter capacidade de suporte nos volumes de água escoadas superficialmente nos períodos chuvosos. Definiu-se locais de análises, no entorno do Campus avançado IFMG, onde estes convergem para o exutório localizado na Ponte do Ribeirão do Corte, escoando águas pluviais das vias Amazonas e José Alvarenga, classificadas como coletora e arterial, respectivamente. O estudo a seguir pauta-se na utilização de uma metodologia aplicável, o qual confeccionará mapa cartográfico através de dados públicos em hidrografia e coleta de informações in loco, fazendo geoprocessamento em ambiente GIS de software livre, o que facilita sua reprodução nos setores públicos. O trabalho fornece elementos de dimensionamentos e hipóteses, para tomada de decisão dos gestores buscando uma melhoria do sistema de drenagem da região e trazendo conhecimento ao público local, os modelos contemporâneos de administração pública, partindo do preceito de uma Smart City, ou seja, com a utilização tecnologia para monitoramento, como possível no QGIS. Desse modo, o município estará preparado para atender suas demandas de crescimento populacional, minimizando gastos com obras emergências no ponto econômico e melhor bem-estar aos munícipes.
\end{abstract}

Palavras-chave: Infraestrutura. Rede de drenagem. Smart city.

\section{BASIC DIAGNOSIS OF THE DRAINAGE SYSTEM IN PIUMHI WITH GIS MODELING}

\section{APPLICATION}

\begin{abstract}
The Brazilian urbanization pattern converged to an inconsistent infrastructure and its chronic problems are historical due to the urban expansion around the springs. Within these challenges, there is an opportunity to insert engineering concepts to remedy these deficiencies. In this study, in the municipality of Piumhi/Minas Gerais, it is observed that the socioenvironmental, impacts caused, through the disordered population growth and corroborated with an old infrastructure, led some points located in the municipality to not

\footnotetext{
${ }^{1}$ Como citar este artigo: Silva, G. S.; MATTOSinHO, G. O. Diagnóstico básico do sistema de drenagem em Piumhi com aplicação de modelagem GIS. ForScience, Formiga, v. 9, n. 2, e00871, jul./dez. 2021. DOI: 10.29069/forscience.2021v9n2.e871.

${ }^{2}$ Autor para correspondência: Gabriel Soares Silva; e-mail: gssilva@ hotmail.com.br.
} 
have the capacity to support the drained water volumes. superficially in rainy periods. Analysis sites were defined around the advanced IFMG campus, where they converge to the exutory located on the Ribeirão do Corte Bridge, draining rainwater from the Amazonas and José Alvarenga roads, classified as collector and arterial, respectively. The following study is based on the use of an applicable methodology, which will make a cartographic map using public data in hydrography and information collection in loco, doing geoprocessing in a free software GIS environment, which facilitates its reproduction in the public sectors. The work provides elements of dimensioning and hypotheses, for decision-making by managers seeking to improve the drainage system in the region and bringing knowledge to the local, public about contemporary models of public administration, based on the precept of a Smart City, that is, with the use technology for monitoring, as possible in QGIS. In this way, the municipality will be prepared to meet its population growth demands, minimizing expenses with emergency works at the economic point and better well-being for residents.

Keywords: Infrastructure. Drainage system. Smart city.

\title{
1 INTRODUÇÃO
}

As demandas por obras de engenharia que sejam cada vez mais eficientes e menos impactantes são de grande notoriedade desta década. A adoção de medidas estruturais isoladas está cada vez mais perdendo espaço para soluções híbridas e mais tecnológicas, que faz o mercado ser desafiador. Um fator preponderante desta análise é que o Brasil historicamente possui, em seu padrão de urbanização, uma condição de expansão urbana entorno de Córregos, Ribeirões e Rios. Com um crescimento urbano precário e desordenado, sendo autoproduzidos pelos próprios moradores e gestores públicos.

\begin{abstract}
O aumento das áreas urbanizadas e consequentemente, impermeabilizadas, ocorreu a partir das zonas mais baixas, próximas às várzeas dos rios ou à beira-mar e, direção às colinas e morros, em face da necessária interação da população com os corpos hídricos, utilizados como fonte de alimento e dessedentação, além de via de transporte (CANHOLI, 2014, p. 15).
\end{abstract}

Há relato datado $1575^{3}$ que a má administração no uso e ocupação do solo já acarretava a impermeabilização do terreno às margens do curso da água, no povoamento em morros ou trecho de grande declividade limitando o escoamento da água na superfície e dificultando a penetração no solo. Com os passar das décadas, esses problemas de engenharia e infraestrutura ainda circundam nos debates políticos e sociais, haja vista que todos os anos se enfrentam desastres pelos efeitos da ação natural das chuvas.

Os desafios atuais em gestão pública não são poucos, já que não se trata apenas de expandir a infraestrutura das cidades para absorver um crescimento futuro, uma vez que o

\footnotetext{
${ }^{3}$ Em 1575 Na cidade de São Sebastião do Rio de Janeiro, o padre José de Anchieta relatou em uma carta para outro jesuíta contando sobre a força das chuvas: "[...] choveu tanto que se encheu e estouraram as fontes da nova cidade [...]".
} 
processo político estabelecido se instituiu por um modelo marcado de disparidades socioespaciais, ineficiência e grande degradação ambiental (ROLNIK; KLINK, 2011).

Carvalho, Paula e Gonçalves (2018) pautam-se no conceito da necessidade de uma boa infraestrutura, entretanto compreende a dificuldade de uma gestão pública em projetos que se exigem um entendimento técnico-científico mais apurado.

As crescentes exigências por obras de infraestrutura nos países em desenvolvimento, associadas ao aumento da complexidade dos projetos, têm gerado importantes desafios para a gestão de obras públicas. [...] destaca-se a criação de formas de contratação e de administração dos projetos que evitem os aumentos de custo e prazo (CARVALHO; PAULA; GONÇALVES, 2018, p. 01).

Dentro do que é apresentado, observa-se que a ineficiência da infraestrutura é uma situação trivial vivenciada em municípios brasileiros, onde há falta de planejamento e execução adequada de projetos. Tais projetos não atendem a expansão urbana, acarretando diversos problemas de gestão e planejamento. Rolnik e Klink (2011) citam que os recursos são disponibilizados para os governos estaduais e locais, entretanto não se observa mudança significativa nos processos de gestão e ordenamento do solo, assim como nos investimentos em desenvolvimento urbano.

Tal situação explicitada, no trecho acima, é uma realidade vivenciada no município de Piumhi, situado no centro-oeste do estado de Minas Gerais (Figura 1), que segundo dados Instituto Brasileiro de Geografia e Estatística (IBGE, 2019) possui aproximadamente 34.600 habitantes. O município exerce uma grande influência na macrorregião, principalmente no setor turístico, sendo conhecida por porta de entrada da Serra da Canastra e um potencial econômico elevado com produção de café e leite. Em características geomorfológicas, o município de Piumhi possui um vale interior de declividade acentuada, na localidade há existência do Ribeirão do Corte (manancial que atravessa a cidade) situado em um vale central que recebe grande parcela das águas pluviais tornando sua planície em zonas de inundação, que é habitada em determinados trechos. 


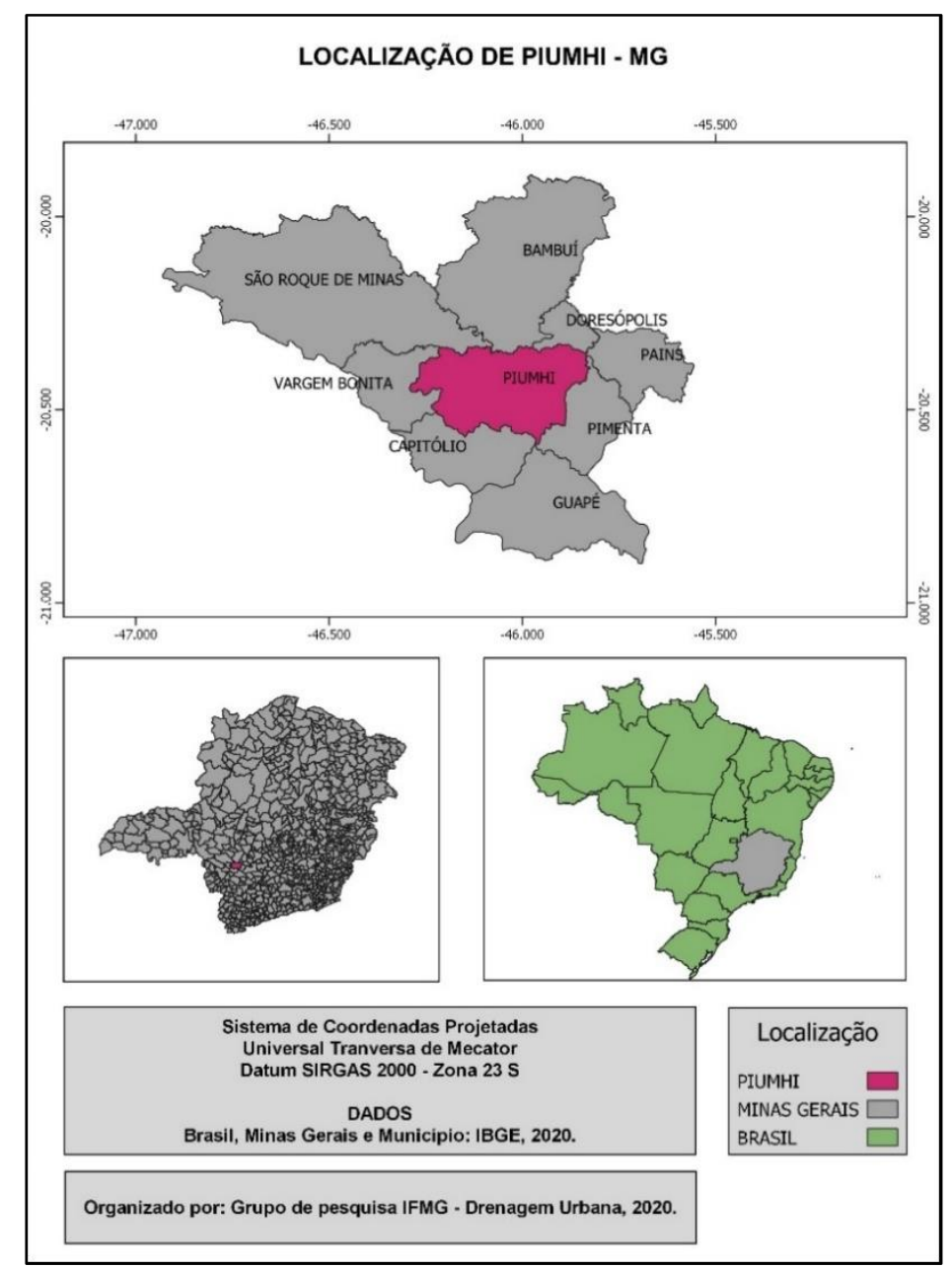

Figura 1 - Representa a localização geral do município diante do estado Fonte: Arquivo pessoal, grupo de pesquisa IFMG (2020).

A rede de drenagem municipal apresenta-se ineficiente e é sobrecarregada pela criação de novos loteamentos na região que se intensificaram. Em grande parte, os empreendimentos localizam-se em trechos de maior altitude e geraram alta impermeabilização do solo, que vai na contramão das premissas da recente lei de uso e ocupação do solo municipal, implementada no Plano Diretor (atualmente é vigente da Lei Complementar $n^{\circ} 70$, de 18 de março de 2020 Parcelamento, Uso e Ocupação do Solo que define a porcentagem de cobertura do terreno).

Vale ressaltar que os loteamentos foram executados enquanto não havia lei municipal que preservava porcentagens de área permeável obrigatória, como na referida lei de 2020.

Após o tema de pesquisa ser proposto em 2018, verificou-se uma recorrência crônica de alagamentos nos mesmos pontos (Figura 2). A ausência de dados históricos acerca do conteúdo dificulta os registros da temática, entretanto algo que foi registrado pela Rádio 104,3 FM e publicado em perfil na rede social (Facebook) auxiliou no enriquecimento e direcionamento do trabalho. No mês de fevereiro de 2019, após uma onda de intensas chuvas, 
a área de estudo mais uma vez não suportou a demanda e ocorreu inundação e em uma entrevista o secretário de obras do município falou sobre a situação.

Segundo o secretário de obras, Edson "Baiano", os serviços de manutenção estão sendo feitos em diversas ruas e avenidas da cidade, em trechos que se encontram com o asfalto danificado, dificultando a mobilidade urbana. A solução, segundo ele, é implementar um sistema de drenagem fluvial, que irá direcionar o acúmulo de água da chuva para a lateral dos passeios, aliviando o impacto no meio da via. (Reportagem da Rádio 104,3 FM, via Facebook, 2019).

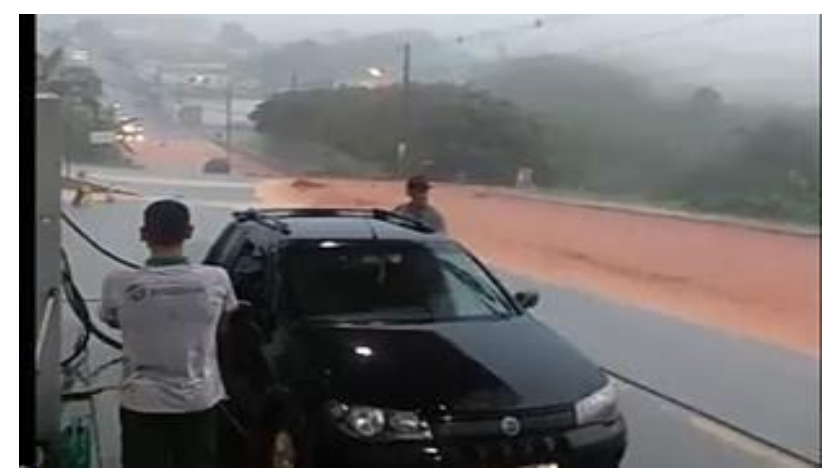

Figura 2 - Forte chuva atingida na Rua Amazonas dia 13/02/19

Fonte: Publicado em grupo de rede social (2019).

A abordagem executada pelo município, mais uma vez, mostrou-se ineficiente, já que em janeiro do ano corrente também se verificaram inundações. Desse modo, a publicização de medidas técnicas e viáveis com alto potencial de resolução da problemática faz se necessária e visa auxiliar o poder público a garantir maior segurança e conforto à população.

Assim exposto, o trabalho, estabelecendo um paralelo com o conceito abordado por Canholi (2014), executou uma metodologia utilizando a modelagem em Geographic Information System (GIS) para determinar a área de influência da "micro-bacia" de drenagem com o objetivo de correlacionar o conceito GIS ao Smart Citypor meio de software livre QGIS 3.4.10. Será executado geoprocessamento, que facilitará aos gestores públicos replicar a metodologia para identificação de áreas que sofram impactos pela ineficiência da rede de drenagem. Ademais, são apresentadas propostas de solução para a zona de estudo, tendo por finalidade atingir o objetivo de corroborar com uma melhor administração pública indicando regiões, que sofrem sistematicamente com problemas devido ao escoamento fluvial superficial.

\section{REFERENCIAL TEÓRICO}


Os alagamentos urbanos causam diversos prejuízos, não apenas naturais, mas perdas econômicas e humanas de acordo com sua intensidade e volume (TUCCI, 2006). Dentre as soluções que podem ser empregadas em drenagem urbana, tem-se duas divisões características de acordo com sua natureza, as medidas estruturais e as não estruturais.

Partindo do princípio de medidas não estruturais, que se busca evitar grandes intervenções, são empregados conceitos básicos e inovadores de drenagem conforme a metodologia empregada por Canholi (2014).

\begin{abstract}
Os conceitos "inovadores" mais adotados para a readequação ou o aumento da eficiência hidráulica dos sistemas de drenagem tem por objetivo promover o retardamento dos escoamentos, de forma a aumentar os tempos de concentração e reduzir as vazões máximas; amortecer os picos e reduzir os volumes de enchentes por meio da retenção em reservatórios; e contar, tanto quanto possível, o run-off no local da precipitação, pela melhoria das condições de infiltração, ou ainda em tanques de contenção (CANHOLI, 2014, p. 16).
\end{abstract}

Já no ponto de vista tecnológico, Afaneh e Shahrour (2017) afirmam que devemos gerenciar, quantificar e qualificar os pontos de interesse. Para Haas et al. (2018) as técnicas empregadas em um ambiente GIS cada vez mais se tornam aliadas ao planejamento ambiental devido à sua eficácia para produções dos diagnósticos com representações expressas em mapas.

Afaneh e Shahrour (2017) expressam a importância do conceito de Smart City com modelagem GIS, na qual o estudo realizado foi proferido na Universidade de Lille na França, onde mostra aplicação do GIS sendo utilizada para um gerenciamento de dados operacionais de um projeto Smart City sendo feito da seguinte forma: cadastramento e georreferenciamento das redes de água potável, esgoto, rede elétrica e aquecimento urbano.

Esses elementos tornam a modelagem em GIS um recurso muito eficiente para o cadastramento destes ambientes para que possa (em uma linguagem simplória) esboçar um mapa com todos os pontos de interesse urbano. Esse tema vem sendo amplamente debatido por meio do ArcGIS Urban, que possui recursos de direcionamento habitável e até de previsão de crescimento demográfico e suas implicações diante do ambiente selecionado. Mundialmente, trabalhos e pesquisas semelhantes estão envolvidos neste tipo de nicho e/ou que envolvam caracterização de ambientes.

Como uma metodologia similar à apresentada por Afaneh e Shahrour (2017), dentro deste projeto, utilizou-se de um software livre para uma aplicação de tais técnicas visando, quantificar os problemas e, após suas interpretações dos dados obtidos apontar possíveis medidas de correção, que podem ser estruturais ou não. 


\section{MATERIAL E MÉTODOS}

O processo metodológico se dá por meio do geoprocessamento dos dados obtidos de forma pública, como o caso da hidrografia e topografia, bem como informações textuais que irão compor nosso resultado cartográfico, seguindo o que é recomendado pelo Manual do IBGE (Figura 3).

O principal ponto de partida é compatibilização desses dados buscando transparecer de forma pública em um software livre, tornando replicável.

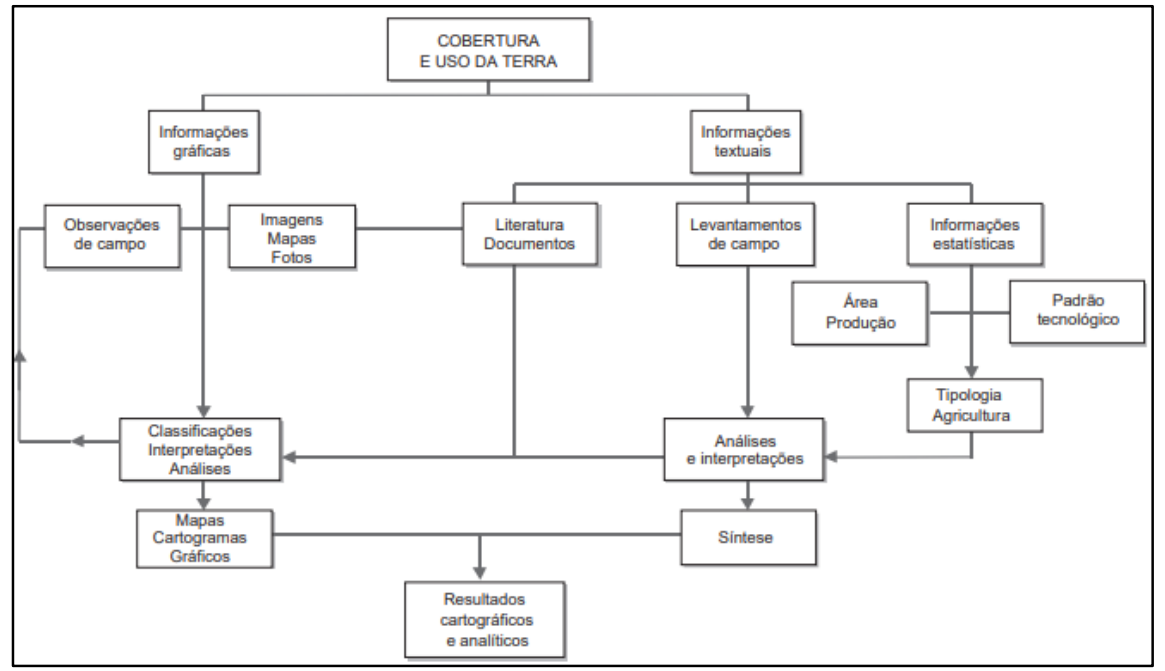

Figura 3: Etapas de levantamento e classificação da cobertura e do uso da terra Fonte: Manual Técnico em Geociências, Cobertura e Uso da Terra, IBGE (2019).

O processo de modelar é de certa forma interpretado como "lapidar algo bruto", ou seja, decompor dados reais e gerais em sistemas simplificados, usando como suporte diversos tipos de linguagem para unificar em único dado em forma de camadas (SOARES FILHO, 2000).

Nesse sentido, a modelagem das informações de dados coletados públicos possui duas fontes vitais: IDE - Sisema e TOPODATA, onde respectivamente obteve-se dados da hidrografia municipal e os Modelos Digitais de Elevações (MDE). Tais plataformas disponibilizam seus documentos com formatos compatíveis a um software de geoprocessamento como o caso do QGIS 3.10.4.

\subsection{Geoprocessamento}

O trabalho de Sensoriamento Remoto inicia-se com a delimitação dos limites geográficos da zona de estudo. Pelo fato deste local se tratar de um escoamento superficial, 
pode-se delimitar amicrobacia hidrográfica (Figura 4) com base do sistema do Instituto Mineiro de Gestão das Águas (IGAM). Os dados vetoriais estão presentes no Web GIS IDESisema (arquivo shp. shapefile) o qual é possível realizar recortes da região.

Paralelamente, as informações topográficas são extraídas por meio de um Modelo Digital de Elevação (MDE) disponível pelo Instituto Nacional de Pesquisas Espaciais (INPE), com a base de dados atualizada em novembro de 2011 (plataforma chamada Banco de Dados Geomorfométricos do Brasil (TOPODATA)), sendo possível adquirir “folhas"cartográficas de declividade e altitude (podendo realizar mapas de curvas de níveis e declividade). Esses arquivos encontram-se em formato raster (matricial) e no ambiente QGIS tem a possibilidade de extrair contorno, gerando curvas de níveis com espaçamento de acordo com sua necessidade.

Outro ponto importante para análise da ocupação do solo é pelas imagens de satélite da missão espacial Landsat, adquiridas na base de dados Norte Americana da United States Geological Survey (USGS). Este processo é trabalhado com imagens multiespectrais irradiadas, que em formatos de bandas geram uma composição de características RGB (Red, Green e Blue). Realizando o processo de unificação da mesma (tecnicamente chamado de miscelânea) é possível contrastar a coloração de vegetação perímetro urbano e corpo hídrico. Efeitos desse processo estão expressos nos resultados.

Tais arquivos extraídos possuem formato Vetorizado em forma de Shapefile e camada Raster georreferenciada, o que permite a utilização de softwares à base do sistema GIS para modelagem local destes documentos: realizar delimitação da bacia e utilizaras observações de campo, além da anotação das variações topográficas e, pelo QGIS acompanhado a curvas de níveis e suas convergências. O resultado está contido no mapa da Figura 4 reunindo os dados topográficos de curvas de nível, as variações de declividade e a bacia delimitada. Ressalva-se que é imprescindível a execução de georreferenciamento com GPS de alta precisão, o que não foi possível nessa primeira abordagem. Todavia, as análises globais não foram prejudicadas e pontos críticos foram localizados e validados com observações em campo.

Outro processo que compõe esse estudo, sendo este o mais importante, realizou-se com trabalho de campo coletando dados de quantidade, situação e dimensionamento das bocas de lobos (BL) (Figura 5 apresenta as BL existentes que estão distribuídas pela área de contribuição), além de geometria das vias, calçadas e sarjetas. 


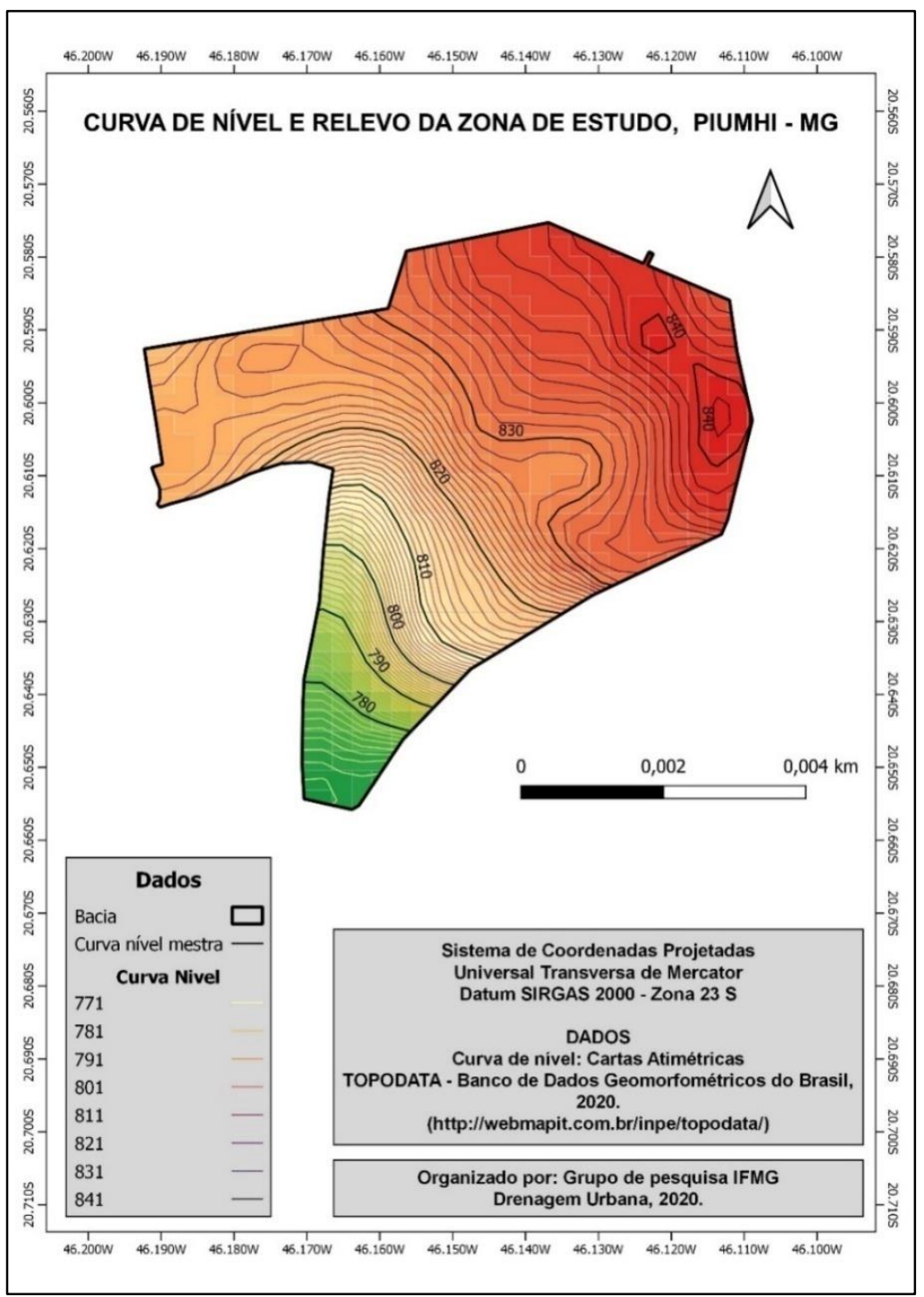

Figura 4 - Mapa Curvas de Nível da Bacia Fonte: Arquivo Pessoal (2020).

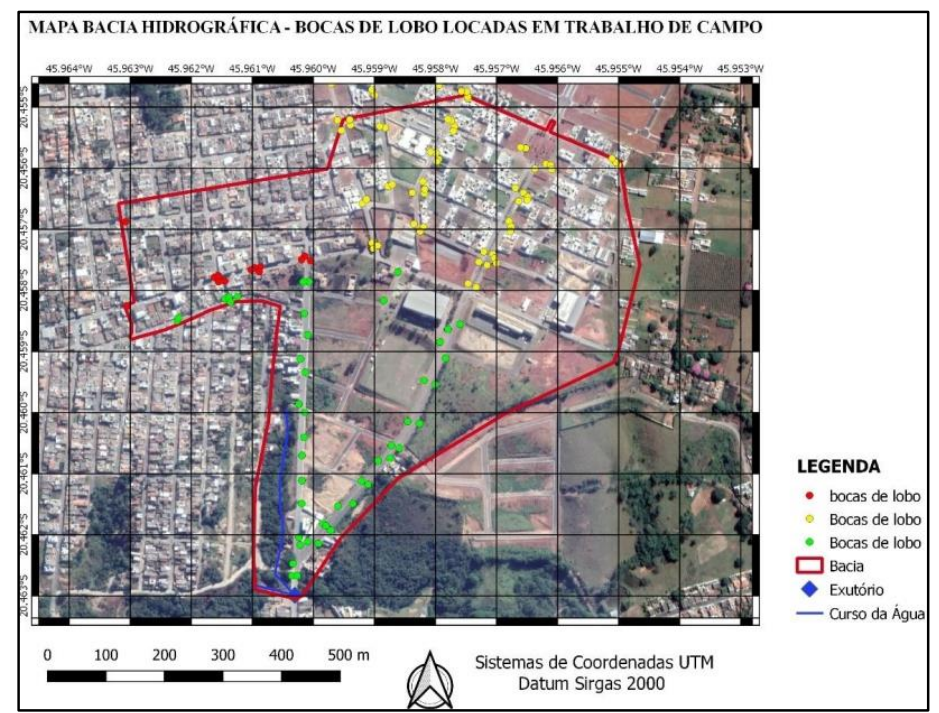

Figura 5- Mapa da Bacia com as bocas de lobo locadas. Fonte: Arquivo Pessoal (2019). 


\subsection{QGIS}

As inserções dos dados importados é o primeiro passo dentro do software. A hidrografia no formato vetorial, já os MDE e imagens do Landsat em arquivo TIFF. No QGIS, as janelas de vetor e raster subdividem estas duas informações, respectivamente. A primeira ação é trabalhar as informações topográficas identificando as cotas de elevação para qual converge no exutório (ponto de menor cota da bacia). Os dados de hidrografia fornecem os mananciais que permeiam a região de análise, sendo essa a segunda etapa caracterizada por um recorte vetorial.

A partir destas bases é possível confeccionar um mapa cartográfico com suas divisas e verificando quais bairros estão internos a essa área. Desse modo, com as informações topográficas e hidrográficas, tem-se os dados fundamentais do projeto expressos nos mapas supracitados.

A classificação Sensorial Remota auxilia na análise percentual da atual condição de Uso e Ocupação do Solo. Nesse processo, a imagem obtida pelo voo do satélite Landsat é compilada nas opções de mesclagem no QGIS e realiza-se no software a classificação sistemática de elementos reconhecíveis com auxílio do plugin Dzetsaka, o qual devolve um arquivo raster com as classificações programadas.

\subsection{Equações fundamentais}

Com os dados adquiridos utilizou-se tabela de cálculo baseada no manual Departamento Nacional de Infraestrutura de Transportes (DNIT) para dimensionamento de quantidade e geometria de BL a partir dos dados de vazão, declividade da via, altura e capacidade da sarjeta, quantidade mínima de boca de lobo e sua capacidade (apresentadas a seguir). Ademais, foram confrontados a quantidade e localização das BL do projetado nesse estudo com o disponível em campo.

\section{Vazão da Chuva}

$Q=(C \times i \times A) \div 360$

Equação 01

$\mathrm{Q}$ : vazão de precipitação $\left(\mathrm{m}^{3} / \mathrm{s}\right)$;

C: Coeficiente de escoamento superficial;

I: intensidade pluviométrica $(\mathrm{mm} / \mathrm{h})$;

A: área de contribuição acumulada (ha).

\section{Declividade da via}

$I=\frac{\left(\cot _{m}-\operatorname{Cot}_{j}\right)}{L} \quad$ Equação 02 
$\operatorname{Cot}_{m}:$ Cota montante $(\mathrm{m})$

$\operatorname{Cot}_{j}$ : Cota jusante $(\mathrm{m})$;

$\mathrm{L}$ : comprimento da via (m).

\section{Capacidade da sarjeta}

$$
\mathrm{Qs}=\left(0,375 \times \sqrt{I \times z \times y_{0}^{8 / 3}}\right) / \mathrm{n}
$$

Qs: Capacidade de uma sarjeta $(\mathrm{L} / \mathrm{s})$;

$y_{0}$ : Altura máxima de água na guia $(\mathrm{m})$;

$\mathrm{z}$ : inverso da declividade transversal $(\theta)$;

I: inclinação longitudinal da sarjeta (greide da rua);

$\mathrm{n}$ : coeficiente de rugosidade de Manning.

\section{Largura de água na sarjeta}

$L_{s}=z \times y_{c}$

Ls: largura de água na sarjeta (m);

$\mathrm{z}$ : inverso da declividade transversal $(\theta)$;

$y_{c}$ : altura de água calculada na sarjeta sem boca de lobo (m).

\section{RESULTADOS E DISCUSSÃO}

Por meio da imagem simplificada do satélite Landsat 8 OLIe Landsat5 TM, feito pelo download da USGS, é possível identificar que grande parte da zona de estudo é ocupada por área urbana, ou seja, quase toda impermeabilizada (Figura 6) quanto ao uso e ocupação do solo somente na região de estudo. Ressalta-se que devido a essa aproximação feita do Landsat os pixels geram uma distorção. Subdividido entre três características distintas (Áreas Urbanas, Pasto e Vegetação nativa) tem-se resultados satisfatórios quando se compara a Figura 6 com a Figura 7 e é nítido o crescimento urbano.

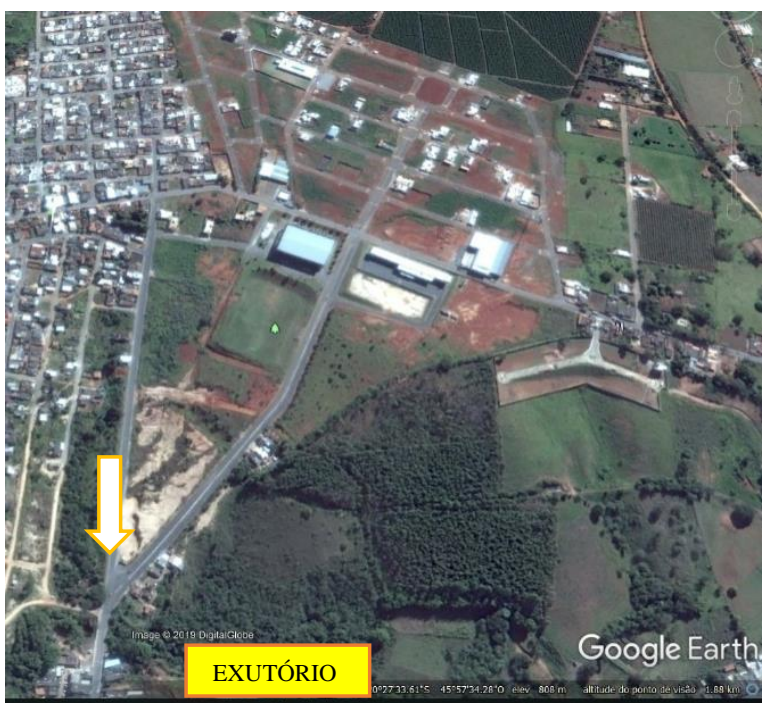

Figura 6- Mapa satélite de 2013

Fonte: Google Earth (2019).

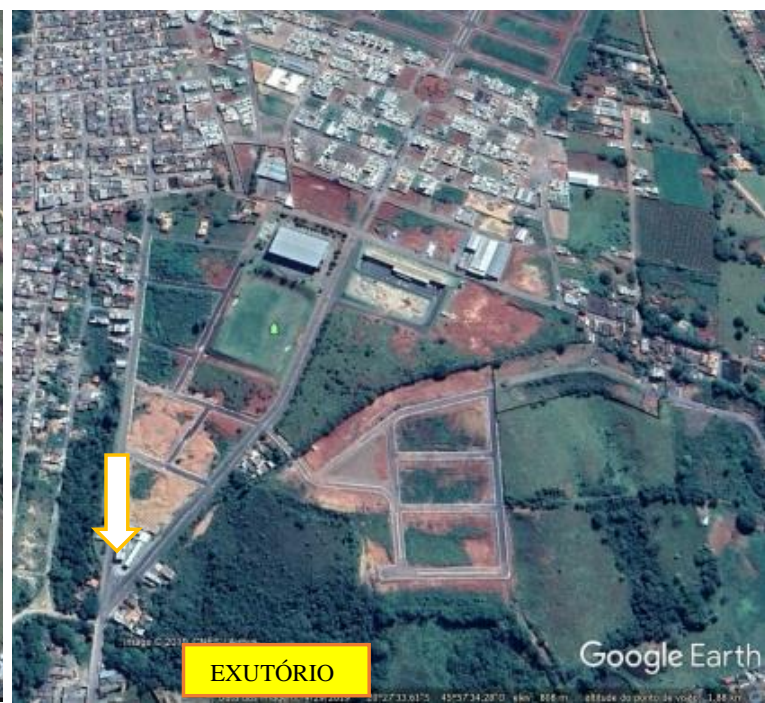

Figura 7 - Mapa satélite de 2019

Fonte: Google Earth (2019). 


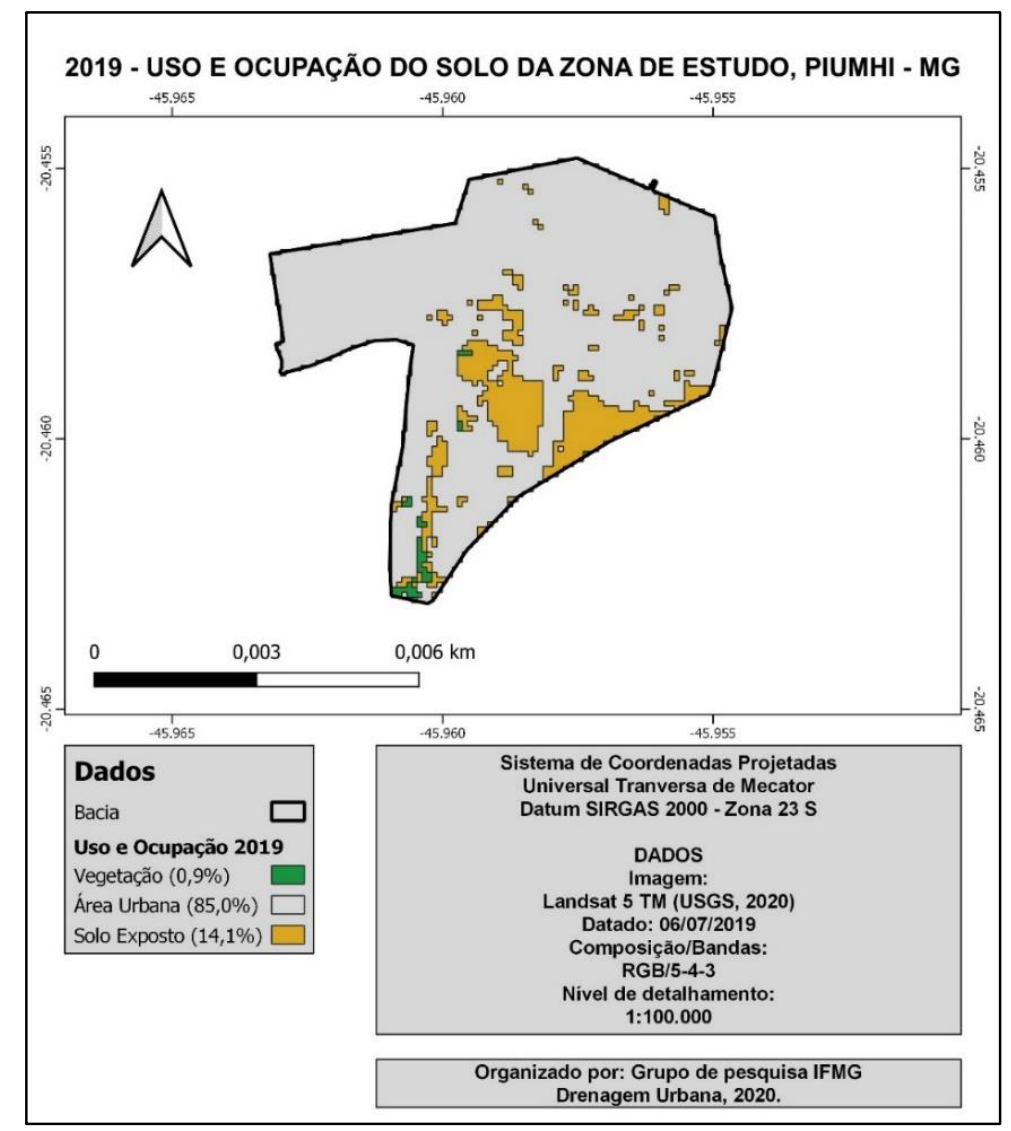

Figura 8 - Mapa de uso e ocupação do solo somente na zona de estudo 2019 Fonte: Arquivo Pessoal (2020).

Observa-se pelos mapas que existe grande convergência de um alto fluxo de escoamento superficial e da rede drenagem no sentido do exutório, ocasionando um baixo tempo de concentração e uma alta velocidade de vazão. Dessa maneira, pode-se afirmar que o curso d'água a jusante é altamente influenciado pela declividade da via, altura da sarjeta, além dos parâmetros discutidos como topografia e expansão urbana desordenada, que reduz área de permeabilidade do solo.

Salienta-se que a resolução das imagens interfere na valoração de áreas, para tal recomenda-se o uso do satélite nacional CBERS-4 (China-Brazil Earth-Resources Satellite), todavia a base de dados ainda possui defasagem nas informações.

O escoamento superficial é intensividade devido às obstruções das bocas de lobos (Figuras 9 e 10) onde, basicamente, impede quase que, por completo, a entrada de água (boca de lobo perde sua função). Com isso, o fluxo da água persiste em um escoamento superficial, sendo um problema condicionado a uma ineficiência da manutenção pública no setor de limpeza urbana. 


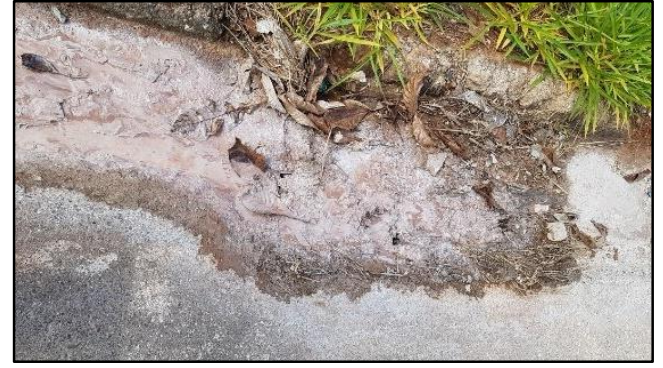

Figura 9 - Boca de Lobo completamente obstruída Fonte: Arquivo Pessoal (2019).

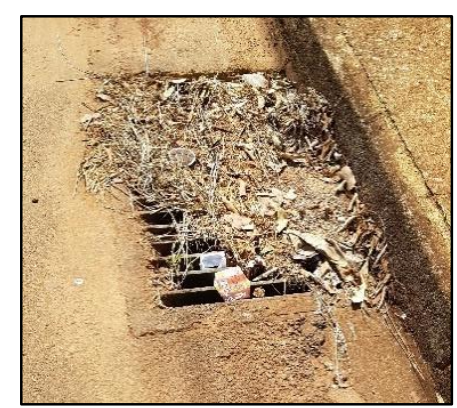

Figura 10 - Boca de lobo com Resíduos Fonte: Arquivo Pessoal (2019).

No trabalho técnico-científico, verificou-se que há trechos sobrecarregados e em desacordo com o dimensionamento preconizado pelo DNIT (convencional), uma vez que há menos bocas de lobo do que o calculado e, devido à obstrução na boca de lobo, o volume que seria drenado é repassado para o trecho seguinte.

Essa contribuição extra de fluxo de água que as bocas de lobo anteriores não drenaram faz com que o volume quase dobre na segunda e assim por diante. Esse fato é um dos pontos críticos que gera inundações já que não há capacidade de suporte.

No trabalho de campo foi executada alocação e identificação das bocas de lobos e se observou ao todo 125 bocas de lobo, que setorizadas por bairros condicionou-se a nomenclatura de setor 1, 2, 3 e 4 (Figura 11). Executados os dimensionamentos verificou-se no setor 1 uma baixa drenagem.

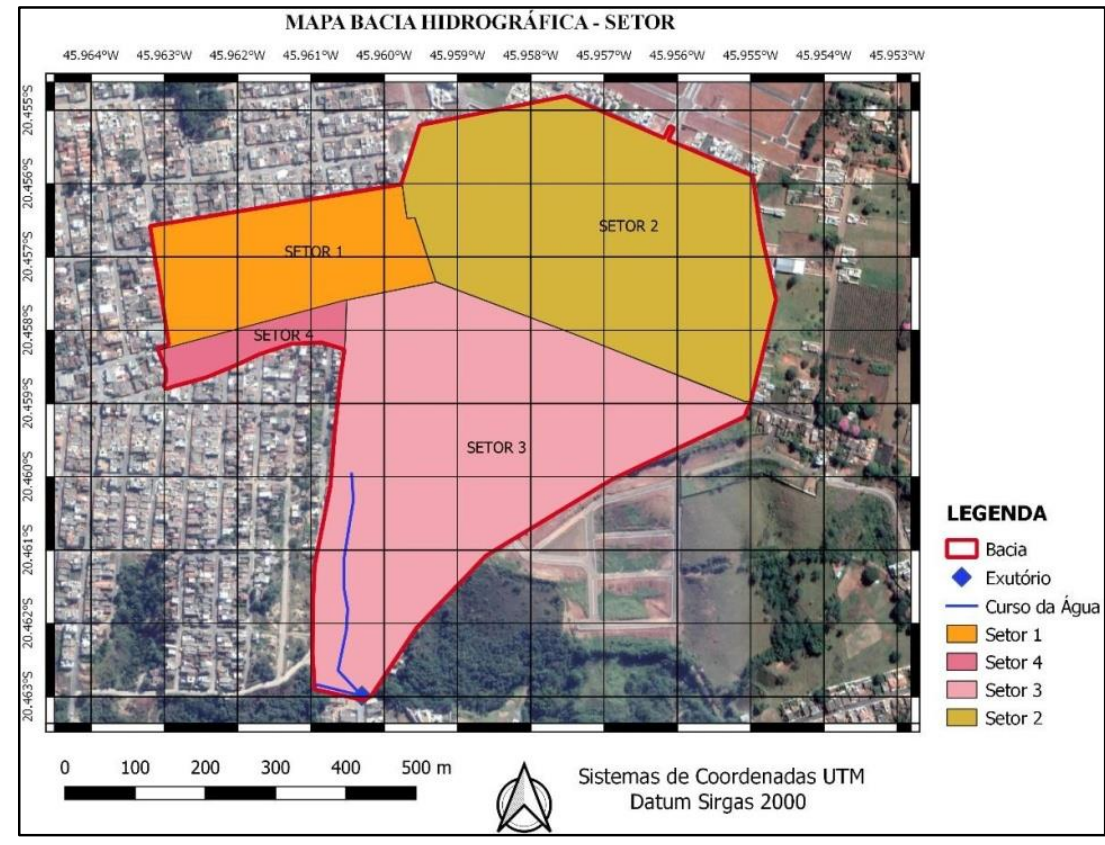

Figura 11- Mapa por Setores

Fonte: Arquivo Pessoal (2019). 
Entretanto, historicamente, o setor 1 já exista em relação aos demais e a rede atual tinha capacidade para tal vazão (vazão sem contribuição extra). Todavia, quando do processo de expansão urbana, a rede de drenagem não foi atualizada e não se considerou o grande número de empreendimentos impermeabilizando o solo assim como visto nas Figuras 6 e 7 . Aos demais locais como setor 2 (bairro Pérola Negra) apresentou uma certa consistência em quantidade observada e dimensionada, mas se observou que falta manutenção as bocas de lobos existes, pois, grande parte se encontra com excesso de sujeira e resíduos de construção civil que obstrui a entrada de fluxo de água e aumenta o escoamento superficial.

Diante deste trabalho foi possível traçar e sistematizar regiões que geram conflito de drenagem urbana dentro dos bairros escolhidos. Por meio das planilhas de cálculo, apresentou como resultado a escassez de bocas de lobo no setor 1 e geometria deficiente das vias entre os setores 1 e 4. Observou-se a ausência de manutenção sanitárias no setor 4. A soma destes fatores corrobora para alto volume da vazão nas vias de maior declividade. Quanto aos setores 3 e 2, as observações in loco, bem como as planilhas, identificaram-se condições positivas no aspecto quantidade de bocas de lobos, todavia a limpeza urbana encontra-se em situações precárias e ausentes, propõe-se então uma gestão ambiental eficiente, diante de tais parâmetros.

Este trabalho busca contribuir com gestores públicos, desse modo, apresenta-se algumas medidas paliativas não estruturais, definidas por Canholi (2014) como sendo eficazes e de custos mais baixos como exemplo: ações de regularização do uso e ocupação do solo, assim como sistemas de alerta de chuvas. Outrossim, tal situação requer modernização, que visam mitigar os transtornos causados por essas inundações.

A aplicação da Lei Municipal 2019-067 possui dificuldades, pois há pontos em revisão mesmo após o decreto municipal (que se alterou através da Lei Complementar $n^{\circ} 70$, de 18 de março de 2020). De fato, como uma contribuição dos gestores, pode-se apontar a melhor e mais técnica ocupação territorial como uma das soluções. Tal fato vem a corroborar a não intervenção estrutural.

Outro ponto seria a fiscalização mais rigorosa quando ao cumprimento da Lei Municipal 2018-57, que apresenta na seção II, em seu artigo 6, que a conservação e limpeza de passeios e sarjetas é de responsabilidade do proprietário/possuídos, sendo expressamente proibido destinar esses resíduos aos bueiros e bocas de lobo, sendo passível a multa.

No primeiro momento, é necessária a manutenção do sistema existente com maior periodicidade, a fim de garantir o fluxo contínuo das águas das chuvas (sem obstruções), 
estabelecendo compromisso público dessa verificação sempre que anteceder períodos chuvosos, o que aliviará a falta de planejamento urbano.

No segundo momento, medidas estruturais deverão ser aplicadas já que aponta no setor 1 (bairro Novo Tempo) ausência de sistema de drenagem e no setor 1 e 4 (Novo Tempo e parte do Totonha Tomé) geometrias irregulares: vias, sarjetas e calçadas. Busca-se, como sequenciada pesquisa, elaborar Manual de Drenagem para que seja feito levantamento detalhado do sistema existente das suas tubulações subterrâneas e suas ramificações, para dimensionamento detalhado para atualização da rede de drenagem.

Outro ponto fundamental que convergirá para uma cidade de status Smart City é implementação de sistemas de alertas e previsões de inundações. Catalogando todos os pontos de drenagem existentes e gerenciando remotamente a qualidade do sistema, por meio de uma modelagem em GIS, delimitando áreas sujeitas a inundações em função do risco, que apontará eventuais locais onde fatidicamente ocorrem falhas no sistema de drenagem.

\section{CONCLUSÃO}

Realizando um paralelo com o projeto apresentado por Afaneh e Shahrour (2017), verifica-se que o presente estudo atendeu a sua proposta em geoprocessamento, delimitando a região, classificando e cadastrando as informações vitais para viabilidade de todo projeto.

Diante deste estudo, identificou-se alguns entraves acerca da legislação municipal, na qual era branda no ponto de vista do zoneamento urbano (o que se alterou durante a pesquisa pela aprovação de Lei Municipal). Contudo, o trabalho pode aferir tópicos importantes que precisam de maior atenção dos gestores públicos, tais como: limpeza urbana, regularização das geometrias de sarjetas e calçadas além de um trabalho de conscientização social para que se tenha uma destinação correta dos resíduos (seja eles sólidos ou de construção civil).

A pesquisa realizada poderá proporcionar atuação no nicho científico acadêmico, além de uma progressão no mercado de trabalho, com uma maior visibilidade para questão socioambiental em torno de drenagem urbana e suas consequências. Consequentemente beneficiando o bem-estar social da população de Piumhi, acrescentando a isso uma proposta ao poder público, assim como, nas grandes cidades, um manual de drenagem urbana para uma melhor qualidade de gestão.

\section{AGRADECIMENTOS}


Ao Instituto Federal de Educação, Ciência e Tecnologia de Minas Gerais (IFMG) Campus Avançado Piumhi para apoiar o trabalho desenvolvido.

\section{REFERÊNCIAS}

104, Rádio. Chuvas deixam a Rua Severo Veloso em estado crítico. 21 de Fev 2019. Post do Facebook. Disponível em:

https://w,aww.facebook.com/search/top/?q=104\%20fm\&epa=SEARCH_BOX. Acesso em: 01 mar. 2019.

AFANEH, A.; SHAHROUR, I. Use of sun rise smart city project, large-scale demonstrator of the smart city. Conference: 2017 Sensors Networks Smart and Emerging Tecnhnologies (SENSET). 2017.

CANHOLI, A. P. Drenagem urbana e controle de enchentes. São Paulo: Oficina de Textos, 2014.

CARVALHO, M. T. M; PAULA, J. M. P; GONÇALVES, P. H. Gerenciamento de obras públicas e as políticas de infraestrutura do brasil contemporâneo - Governança da Política de Infraestrutura: condicionantes institucionais ao investimento 2018.

SOARES FILHO, B. S. S. Modelagem de dados espaciais: curso de especialização em georreferenciamento. Departamento de Cartografia Centro de Sensoriamento Remoto. Universidade Federal de Minas Gerais/UFMG Belo Horizonte, 2000.

HASS, A. et al. Delimitação e caracterização de app através do uso de um sistema de informação geográfica (SIG): o caso das app's nos cursos de água da sub-bacia do lajeado pardo, noroeste do RS. Revista gestão sustentável ambiental, Florianópolis, v. 7, n. 3, p.640649, jul/set. 2018

IBGE - Instituto Brasileiro de Geografia e Estatística. Disponível em: https://ibge.gov.br/ Acesso em: 29 fev. 2020.

ROLNIK, R; KLINK, J. Crescimento econômico e desenvolvimento urbano. Novos Estudos. - CEBRAP no. 89, São Paulo, mar. 2011.

TUCCI, C. E. M. Inundações urbanas. In: TUCCI, C. E. M.; PORTO, R. L. L.; BARROS, M.T (Eds.). Drenagem urbana. Porto Alegre: ABRH/ Editora da Universidade/UFRGS, cap. 1, p. 15-36, 2006.

SNIS - Sistema Nacional de Informações sobre Saneamento. Disponível em: http://www.snis.gov.br/. Acesso em: 25 abr. 2020. 


\section{DADOS DOS AUTORES:}

Nome: Gabriel Soares Silva

E-mail: gssilva@hotmail.com.br

Curriculum Lattes: http://lattes.cnpq.br/1061564521582561

Graduando do curso de Bacharelado de Engenharia Civil pelo IFMG campus Piumhi, com experiência de pesquisas acadêmicas nas áreas de: Hidrologia e Gestão Hídricas, além de Drenagem Urbana, participante do Grupo de Pesquisa em Ciências Ambientais, Econômicas e Sustentabilidade projeto de Iniciação Científica, certificado pelo $\mathrm{CNPq}$, atuando nos seguintes temas: em Capitólio, análise de Sensoriamento Remoto por meio do software livre QGIS e estudos de geoprocessamento de dados para análise de recuperação de mananciais e recursos hídricos no Córrego do Grotão, pertencente a sub-bacia do Lago de Furnas - Capitólio - Minas Gerais.

Nome: Germano de Oliveira Mattosinho

E-mail: germano.mattosinho@ifmg.edu.br

Curriculum Lattes: http://lattes.cnpq.br/7428922825084519

Engenheiro civil, mestre e doutorando em engenharia mecânica na área de mecânica dos fluidos. Atuo em graduação em Engenharia Civil desde 2016 lecionando as disciplinas da área de Hidráulica e Saneamento em instituições públicas de ensino. Atuo em projetos e consultorias nas áreas de infraestrutura, proteção e recuperação ambiental e instalações prediais. Professor EBTT no IFMG Campus Piumhi desde fev/2017. Contato:germano.mattosinho@ifmg.edu.br. 